\title{
Kaldorian boom-bust cycles in the housing market
}

\author{
Ingo Barens*, Peter Flaschel ${ }^{* *}$, Florian Hartmann ${ }^{* * *}$ \\ and Andreas Röthig ${ }^{* * * * *}$
}

\begin{abstract}
We show that the Kaldor (1940) trade cycle mechanism can be meaningfully applied to the market for residential housing space, since the demand for houses may be positively related to the housing price in a mid-range price domain, while it is downward sloping for house prices sufficiently small as well as sufficiently large. Confronted with the current supply of houses this gives rise to multiple equilibria. Then the employed nonlinear house demand schedule is coupled with backward-looking house price expectations and a planar dynamics is obtained with the same range of model-consistent expectations equilibria as in the partial situation studied beforehand. The model however is not dependent on the backward oriented expectation scheme, but also applies to the case of myopic perfect foresight. The nonlinear demand function for houses in connection with changes in the housing stock initiates sudden reversals from booms into busts and vice versa, which from a mathematical point of view give locally rise to fold catastrophes at the bifurcation points, with the dynamics being described by relaxation oscillations from the global perspective.
\end{abstract}

JEL classifications: EI2, E32, R2I, R3I

Keywords: Kaldorian trade cycles, boom-bust cycles, housing markets, relaxation oscillations

* Darmstadt University of Technology.

** Bielefeld University.

*** University of Osnabrück.

**** We would like to thank Peter Skott and two anonymous referees for their helpful comments. Of course, the responsibility for remaining errors is ours.

Correspondence Address:

Florian Hartmann, Institute for Empirical Economic Research, University of Osnabrück, Rolandstr. 8, 49069 Osnabrück, Germany, e-mail: fhartman@uos.de.

Received 22 January 20I0, accepted 2I May 2010

(C) INTERVENTION 7 (2), 20IO, 36I-375 
"Success breeds disregard of the possibility of failures. The absence of serious financial difficulties over a substantial period leads [...] to a euphoric economy in which short-term financing of long term positions becomes the normal way of life. As a previous financial crisis recedes in time, it is quite natural for central bankers, government officials, bankers, businessmen and even economists to believe that a new era has arrived.« (Minsky 1982: 213)

\section{Introduction}

As the bursting bubble in the US housing market was the starting point of the current global financial crisis, it is certainly of great interest and importance to understand which forces drive the housing market and the recurrent boom-bust cycles that could be observed in the US housing market over the past decades. In this respect we want to show that there may be a specific nonlinear economic mechanism at work in the market for residential property which can explain the sudden reversal of a boom into a bust and vice versa.

Our point of departure for the description of such a mechanism characterizing the housing market is Kaldor's (1940) nonlinear approach to the explanation of the trade cycle which we here reinterpret appropriately through a law of motion for housing prices and the expectations driven boom-bust cycle it can imply. In Kaldor's original contribution the business cycle was driven by the nonlinear investment function, the dynamic multiplier process and capital accumulation, while we here adopt a mechanism that initiates boombust cycles in the housing market through house price dynamics, corresponding price expectations and changes in the stock of houses.

The Kaldor-type nonlinear demand schedule is characterized by two shifts in the relationship to the housing price. Confronted with the supply of houses, multiple equilibria arise, among them a boom and a bust equilibrium. This will be a prerequisite to establish later on boom-bust cycles with the help of movements in the housing stock.

Upwardly adjusting supply in housing can in the case of multiple equilibria lead to the loss of the boom equilibrium, implying that the bust equilibrium becomes a global attractor to which prices and expectations converge. Such bust equilibria are interacting with falling supply in housing which sooner or later gives rise to the disappearance of the bust equilibrium and thereafter an upward dynamics to the again existing boom equilibrium. This process will repeat itself as long as the demand schedule for houses remains fixed. It is not dependent on the backward oriented expectation scheme we start from, but also applies to the case of myopic perfect foresight.

It is known from the literature on the Kaldorian trade cycle model (e.g. Chang/Smith [197I], Varian [1979], Lorenz [1993], Tu [1994] and Flaschel [2009]) that this situation can be further analyzed using methods from catastrophe theory as well as relaxation oscillations. A nonlinear demand function for houses in connection with changes in the housing stock thus initiates sudden reversals from booms into busts and vice versa which from 
a mathematical point of view give locally rise to fold catastrophes at the bifurcation points, with the dynamics being described by relaxation oscillations from the global perspective.

In order to relate our model to actual events in the housing market and to give some empirical motivation for the applied Kaldorian mechanism put forth, a short overview of the US-housing market is provided in the next section.

\section{The US residential house market: Some observations}

The popular Case-Shiller house price index, which is based on quarterly data of nominal house prices throughout the US, had its peak in the second quarter of 2006 . This was an all time high which marked the peak of the successively built-up housing bubble. After that point a rapid decline in the index could be observed which reflected the burst of the bubble and therefore the turn from a boom into a bust. No recovery in form of a halt in the downward trend of the index had been visible until summer 2009. All this followed after a boom of almost a full decade of thriving price increases since the year 2000 . For a detailed description of the development see Baker (2008).

In their assessment of housing markets Muellbauer and Murphy (2008) found that agents are driven mainly by psychological forces and therefore cause inherent regularities in the housing price dynamics which seem to be in line with a systematic overvaluation. Housing prices are regarded as being mispriced and markets therefore not efficient. When fundamentals exercise their full pull on prices, corrections may be accompanied by exaggerated expectations of deep falls which are partly self-fulfilling.

In an IMF working paper before the downturn, Schnure (2005) for example gave the following assessment of the market situation:

»[...] while some of these gains reflect catch-up following slow appreciation in previous

years, recent increases have been particularly rapid, and may be ahead of fundamentals."

A change in the structure of the mortgage market from on-balance sheet lending of banks to a system of securitization of mortgages and loans was intended to smooth the stop-go credit cycle in housing finance and, via several transmission channels, to moderate output volatility of the whole economy. For an investigation of diverse feedback channels between the housing market and the macroeconomy see Goodhart and Hofmann (2008).

This liberalization of mortgage markets meant a shift from the local banks to national and global financial markets. Subprime lending became an important business. A huge number of clients endowed with seemingly cheap mortgages in order to purchase their own homes, had a propensity to consume larger than one. It is a simple economic truth that this is not sustainable. Risks were no longer assessed with reasonable regard to the specific borrower. This led to a tremendous underestimation of default risk and eventually became the reason for breaking credit chains and a continuing distrust among banks. Problems arose when the Fed had to increase interest rates and the monthly installments could no longer be afforded by a large part of the mortgagers. 
A variety of explanations were given at that time why the boom could be maintained or might even be followed by a slow appreciation. One reason which was mentioned was the level of house supply. The level was as low as in previous boom-bust cycles when house prices stabilized. In addition, housing supply was less speculative than in the decades before the I990s, indicated by a low level of inventories in relation to the number of house sales (Schnure 2005). This fact suggests the view that a decline in housing demand would not necessarily lead to a large downswing in prices. However, all these optimistic scenarios have been proven wrong.

Instead of price volatility moderation by improved credit allocation, markets were swept with liquidity. Cheap finance combined with an illegitimate practice of lending to private clients without sufficient income fired the price rally first and the foundation was laid for the following breakdown. One has to conclude that the pattern of boom-bust cycles in the housing market had been by far not obsolete, but then stroke back with a vengeance. The following model should highlight a mechanism at work in this particular market.

\section{Kaldorian boom-bust cycles in the housing market}

We explore a highly stylized model of the housing market which features a nonlinear demand function for private housing. The kind of nonlinearity is drawn from the Kaldorian investment function used in his model of the trade cycle. We show that the Kaldor (1940) trade cycle mechanism can be meaningfully applied to the market for private housing, since the demand for houses may be positively related to the housing price in a mid-range price domain, while it is downward sloping for house prices sufficiently small as well as sufficiently large. Confronted with the current supply of houses this gives rise to I or 3 equilibria (booms, busts and unstable). We couple the nonlinear house demand schedule with purely backward-looking house price expectations and get a planar dynamics with the same range of model-consistent expectations equilibria as in the partial situation studied beforehand. At first the model has to be set up via the laws of motion for the price formation and expectations. The demand function must be characterized formally as well.

The demand for houses depends negatively on the price for houses when the stock of houses is either low or high. In the range in between, for a medium domain of the stock of houses, the relationship is however reversed. Rising prices here induce increasing demand and one can interpret that for high as well as low stocks we have the expected normal reaction with respect to house price movements. The reversed reaction can be explained by an overall climate where several factors make people believe that it is generally desirable and practically riskfree to purchase property and become a home-owner. This climate is determined by institutions like the government, the central bank, the media and the financial industry in a rather active way, as well as by social factors like the relative standing in society or demographical developments. All relevant factors for housing demand beside the expected future price of houses could be summarized under this house purchasing climate. Technically speaking all exogenous variables form the climate, whereas the price expecta- 
Figure I: Boom/bust situations: Single and multiple equilibria (for given price expectations)

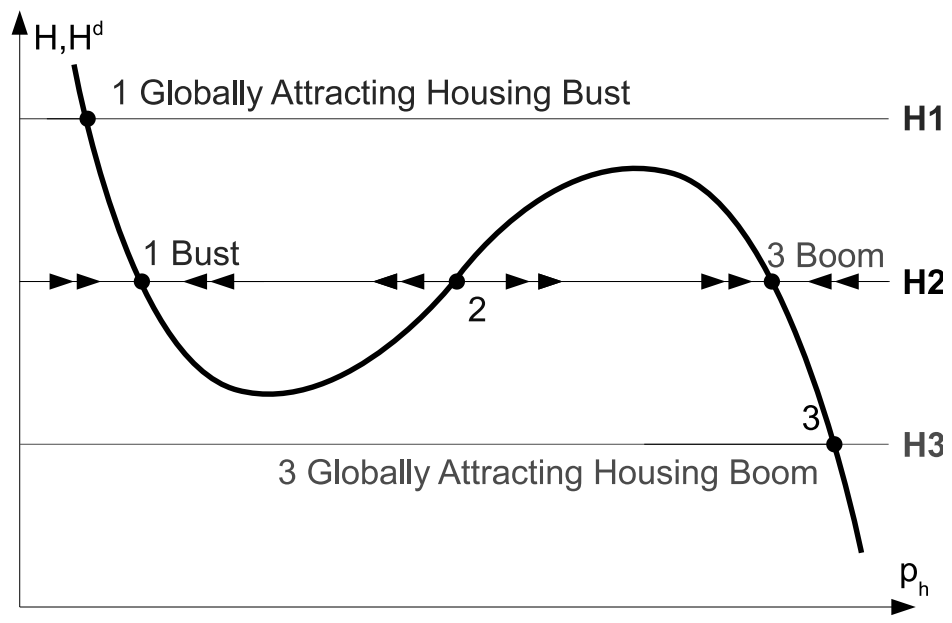

tions will be endogenously determined in the model and thus kept static for the moment. Shiller (2007) finds that the housing boom could be best explained in terms of a psychological theory that sees the investment in housing as a kind of social epidemic. In normal times the general mood does not support a buying frenzy when prices go up. But as soon as several non-price impacts culminate to a critical mass, the usually ultimate factor for a buying decision, the purchasing price, becomes secondary. When switching to the midrange regime of a positive dependency of demand from prices, the climate starts dominating buyers' decisions. Former US-President George W. Bush stated in 2002: „We want everybody in America to own their own home« (Ferguson 2008). A policy promoting this idea contributes to the manifestation of many people's desire to become a home-owner and this the more house prices are rising and thus stimulate their positive attitude to the housing market. Investing money in houses instead of other assets promises a lot of advantages in such a political environment. Housing has always been seen as a secure investment and real-estate seemed to be especially attractive after equity markets went down in the early 2000 . Other asset prices should influence the climate as well as low-interest rates which enable affordability of houses even when prices are high. Moreover, rising house prices increase the value of the collateral. Loose lending practices of banks offered easy access to mortgages for people who were previously excluded from it because of low income or discrimination. Once an atmosphere of massive attractiveness of home-ownership is generated, a kind of keeping-up-with-the-Joneses effect can give additional momentum to housing demand. As buying decisions are not independent from other people's buying behavior in a socio-economic environment, part of the spending behavior is imitated in order not to fall behind and to maintain a relative social status. Consumption patterns are learned from friends or 
neighbors (Lavoie 1994 and 2004). As a consequence of the climate influence rising prices lead to rising demand via an increasing trust in the housing market. However, at a certain level the demand for houses reaches its peak and then starts to decline again with prices rising further. The normal price effect outweighs the positive climate effect then again. Explanations could be the increase of the interest rate by the central bank, market saturation, recovery of other asset markets or a bust in real markets.

After the verbal description and justification of the proposed housing market demand schedule, it will be formalized in the following: We denote by $p_{h}$ the price of houses, by $p_{h}^{e}$ its expected value, by $H^{d}\left(p_{h}, p_{h}^{e}\right)$ the stock demand for houses with $H_{1}^{d} \geq 0$ or $\leq 0$, $H_{2}^{d}>0$ and by $H$ the stock supply. We assume that this stock demand is not fully active at each point in time, but only a portion of it, measured by the parameter $\alpha_{h}$. As percentage excess demand function we therefore postulate the relationship

$$
\alpha_{h} \frac{H^{d}-H}{H}=\alpha_{h} h^{d}\left(p_{h}, p_{h}^{e}\right)
$$

and assume that this determines the growth rate $\hat{p}_{h}$ of the housing prices $p_{h}$ with speed $\beta_{h}$. This basic component of the demand schedule is shown in Figure I for given values of house price expectations and various levels of the stock of houses. Depending on the level of the housing stock $H$ the model can exhibit up to three price equilibria.

We thus assume that the housing market is characterized by the following situations: At equilibrium $\mathrm{I}$ and 3 we have a normal type of housing demand, while around 2 the demand for houses is increasing with their price $p_{h}$. Ignoring $p_{h}^{e}$, equilibria I and 3 are stable, while point 2 is unstable.

We now extend the above situation to the two laws of motion by going from static to backward looking adaptive expectations.

$$
\begin{aligned}
& \widehat{p_{h}}=\beta_{h} \alpha_{h} h^{d}\left(p_{h}, p_{h}^{e}\right) \\
& \widehat{p_{h}^{e}}=\beta_{e}\left(\frac{p_{h}}{p_{h}^{e}}-1\right)
\end{aligned}
$$

This adds the dynamics of house price expectations to those that drive actual house price formation. Equation (2) can be rewritten as

$$
p_{h}^{e}=\beta_{e}\left(p_{h}-p_{h}^{e}\right)
$$

We therefore have a growth law for housing prices that is coupled with a differential equation for house price expectations. The study of this system of differential equations is the subject of the following section. 


\section{Stability analysis}

Under suitable parameter constellations in an economically meaningful range, the postulated laws of motions will give rise to three equilibria when the intensive housing demand function $h^{d}$ equals zero and expected prices equal the current prices. The intensive housing excess demand function $h^{d}$ is zero when supply is exactly met by demand. This causes the price dynamics to come to a halt and the market is put onto the curved isocline. For infinitely fast adjusting price expectations the housing market becomes located at the $45^{\circ}$-line. The intersections of both curves deliver the steady state points of the whole system. Whether the points of rest are stable or not, has to be investigated by evaluating the Jacobians at the respective equilibria. The system has three steady states (see also Figure 2), where $p_{h}^{0}=p_{h}^{e 0}$ holds true. The Jacobian reads at the steady states:

$$
J_{0}=\left(\begin{array}{cc}
\beta_{h} \alpha_{h} \frac{H_{1}^{d}}{H} p_{h}^{0} & \beta_{h} \alpha_{h} \frac{H_{2}^{d}}{H} p_{h}^{0} \\
\beta_{e} & -\beta_{e}
\end{array}\right)=\left(\begin{array}{ll} 
\pm & + \\
+ & -
\end{array}\right)
$$

We assume that

$$
H_{1}^{d}\left(p_{h o}, p_{h o}^{e}\right)+H_{2}^{d}\left(p_{h o}, p_{h o}^{e}\right)<0 \quad \text { if and only if } \frac{-H_{1}^{d}\left(p_{h o}, p_{h o}^{e}\right)}{H_{2}^{d}\left(p_{h o}, p_{h o}^{e}\right)}>1
$$

holds in cases I and 3 , which states that the positive effect of changing house price expectations is dominated by the actual and negative housing price effect as far as marginal changes are concerned. This sum is $>0$ in equilibrium 2. For $\operatorname{det} J$ there holds:

$$
\operatorname{det} J=\beta_{h} \beta_{e} \alpha_{h} \frac{p_{h}^{0}}{H}\left|\left(\begin{array}{cc}
H_{1}^{d} & H_{2}^{d} \\
1 & -1
\end{array}\right)\right|=-\beta_{h} \beta_{e} \alpha_{h} \frac{p_{h}^{0}}{H}\left[H_{1}^{d}+H_{2}^{d}\right]
$$

i.e., we get $\operatorname{det} J>0$ in the equilibria I and 3 and $\operatorname{det} J<0$ in the equilibrium 2, which in the latter case gives a saddle point.

The kind of adjustment to the asymptotically stable equilibria can be stated more precisely. One can show that the stable equilibria are nodes, not spirals by showing that the discriminant $\Delta=\left(\frac{1}{2} \operatorname{tr} A\right)^{2}-\operatorname{det} A$ is of the form $(a-b)^{2}$ and subsequently larger than zero.

The Implicit Function Theorem allows to calculate the slope of the $\dot{p}_{h}=0$-isocline as follows:

$$
p_{h}^{e_{1}}\left(p_{h}\right)=-\frac{H_{1}^{d}}{H_{2}^{d}}>0 \text { in points I and } 3 \text { and } p_{h}^{e_{l}}\left(p_{h}\right)<0 \text { in point } 2 .
$$

The implied situation is depicted in the form of a phase diagram of the dynamics in Figure 2. This figure expands what is shown in Figure I if assumption (4) holds and if $H^{d}(0,0)>0$ is assumed, in which case the origin of the phase space is a saddlepoint. Note however that the basins of attraction of the two stable equilibria are no longer easy to determine though one can conjecture that they are separated by the stable arms of the saddlepoint dynamics. 
Figure 2: The dynamics around the 3 interior equilibria of the model

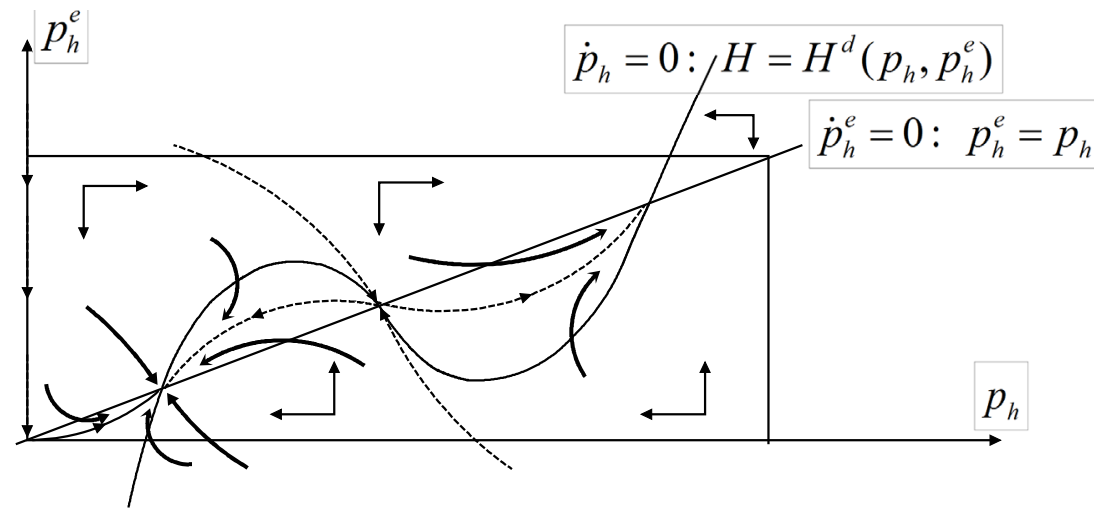

After having shown that local stability exists at least for two of the three equilibria, our concern now is the viability of the global dynamics. We will restrict our analysis to graphical means that will allow for a proper treatment nonetheless. The assumptions made above imply the following global situation in the case where three stationary housing market equilibria exist. Figure 2 shows the dynamics of housing prices and of adaptively adjusting housing price expectations. The drawn box reduces the range of possible values for the variables on economic grounds. A sensitive analysis is needed to restrict the phase space to economically meaningful values of the price variables. First, all negative values can be excluded from the analysis. Furthermore all dynamics on the boundary of the compact subdomain of the phase space point into this domain. This is fairly easy to see, since the housing stock $H$ has not started to move yet and is therefore still a given parameter. The phase diagram as such offers sufficient insight as an analytical device for the moment. Any trajectory starting inside the indicated box will stay inside and converge to one of the two attracting equilibria. The basins of attraction are divided by a separatrix which is equivalent to the stable arm of the saddle equilibrium's dynamics. The global dynamics is not attracted by this equilibrium. Its attracting domain is of measure zero in the domain of all converging trajectories. Therefore an arbitrarily chosen starting point within the box necessarily leads to one of the locally stable equilibria, because the economy is in the basin of attraction of either the lower or the upper equilibrium.

\section{The dissolution of boom and bust equilibria through slowly adjusting housing supply}

Our considerations so far have been concerned with the short run where the housing stock remained fixed. When we take into account that this variable starts moving in time, the situation gives rise to permanently changing regimes with respect to booms and busts similar to what has been investigated for the Kaldorian trade cycle in Varian (1979), see also Flaschel 
(2009, chs. 3,7). The driving force behind these regime changes is the continuously moving stock of houses. Given that the assumption above made regarding the direction of the stock adjustment is true, the increase of housing supply associated with a boom phase gives way to the disappearance of the upper equilibrium. A reduction of the housing supply in connection with an unaltered demand schedule in a bust, causes the lower equilibrium to vanish at one point. In order to leave the analysis tractable in the easiest way without restricting the results, the dissolution of the equilibria shall be done under a perfect foresight expectation scheme which saves us one law of motion, since we have already shown before that the qualitative characteristics with regard to existence and stability of the boom and bust equilibria do not depend on the employed expectation formation scheme.

The situation shown in Figure 2 has a well-defined limit case, as presented in Figure 3, the case of myopic perfect foresight. In this limit case the economy is always on the 45 degree line which is approached vertically with infinite speed. We note that the curved isocline is shifting upwards with increasing housing supply (and thus in the boom phase of this market) and downwards in the bust phase. The housing market is therefore characterized by a tendency that leads to the disappearance of boom equilibria in the boom phase as well as the dismantling of bust equilibria in the bust phase in the course of time. The naive adaptive expectations mechanism leads to results that do not differ qualitatively from the results obtained under the assumption of myopic perfect foresight.

Figure 3: The ideal limit case: Price adjustment under myopic perfect foresight

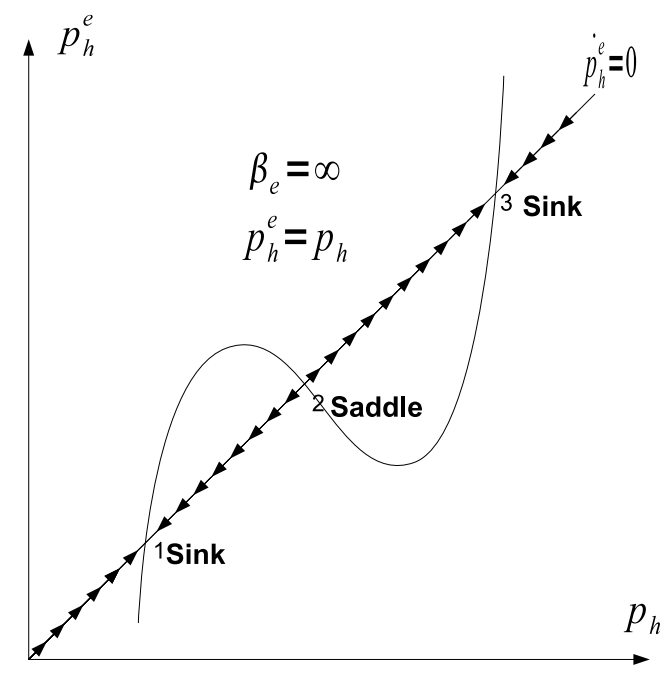

The housing stock $H$ can therefore be interpreted in correspondence to Kaldor (1940) as a slow, continuously changing variable which causes shifts of the $\dot{p}_{h}=0$-isocline. As these shifts might eventually result in the loss of one of the stable equilibria and the saddle point, 
we then get stable booms or busts for a given stock of houses at specific points in time. Adjustment to the unique equilibrium points is ensured by the fast price and price expectation variables. But as the movement of $H$ goes on, e.g. in a boom situation, the market becomes saturated and the supply of houses decreases again. This supply squeeze causes a shift of the isocline back into the direction where three equilibria are reestablished. After some time a point could be reached when the shortage in housing supply becomes so severe in connection with slightly falling prices, that the isocline moves far enough to lose the upper equilibrium and the unstable saddle equilibrium.

A sudden downward jump in housing prices and subsequently in expectations about them occurs. The consecutive process could be characterized by slowly upward moving prices and expectations. Excess capacities are decumulated and the bust reaches its floor. If this process continues with sufficient strength, the $\dot{p}_{h}=0$-isocline will once again intersect with the $p_{h}^{e}=0$-isocline in the three equilibrium points. The bust continues as long as all three equilibria are kept in existence. The bust turns into a boom when supply scarcity requires an upward jump in $p_{h}$, initiated by the loss of the lower stable equilibrium. Figure 2 shows that there should exist a compact subdomain of the whole phase space where all dynamics point inwards everywhere on the boundary. The drawn box only contains values of $p_{h}$ and $p_{h}^{e}>0$. Moreover it should be restricted to non-catastrophic values, since $p_{h}$ and $p_{h}^{e}=0$ are economically not justifiable and might deliver nonreliable results. The subdomain must be limited to price values that are economically reasonable and empirically observable. This would allow to construct a stable limit cycle in the $p_{h}, p_{h}^{e}$-dynamics. This limit cycle would attract all relevant trajectories. No trajectory that originates in the box can leave it. The analysis of the resulting limit cycle must be left here to a graphical treatment.

Figure 4: Bust-driven downward shifting housing supply and the emergence of a single globally attracting boom equilibrium

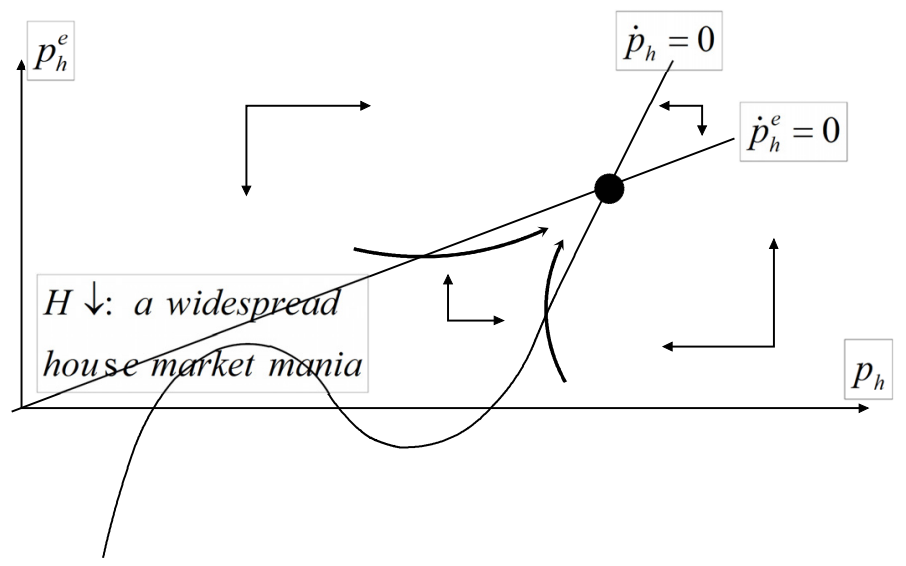




\section{Fold catastrophes and relaxation oscillations in the housing market}

In order to further simplify the analysis we assume myopic perfect foresight of agents in the housing market with respect to the evolution of prices. One of the two laws of motion collapses into an equilibrium condition. For infinitely fast adjustment of the price level expectations, the steady state condition $p_{h}^{e}=p_{h}$ is fulfilled in every point of time. The parameter $\beta_{e}$ approaches infinity in this extreme case. This means instantaneous adjustment to the housing market equilibrium curve, the $\dot{p}_{h}=0$-isocline. So we are left with just one law of motion for the price level. The housing supply can be regarded as a parameter in the short run, but should become a variable in the long run. Employing catastrophe theory the local behavior of the system dynamics can be studied in more detail at the critical points where the boom phase ends and the switching to a bust occurs, respectively the bust ceases and the boom starts. These transitions must be executed by jumping processes of the fast variable, in this case the house price level, from one area of the state space to another. These jumps are called catastrophes. We will investigate here the simplest form of catastrophe, the so-called fold catastrophe. Having classified the stock of houses as the slow and the price level as the fast variable, we can track the interaction of the upper and lower short run equilibria with the long-term dynamics in the $H, p_{h}$-phase space.

Figure 5: Boom-driven increasing housing supply and the return of a globally attracting bust equilibrium

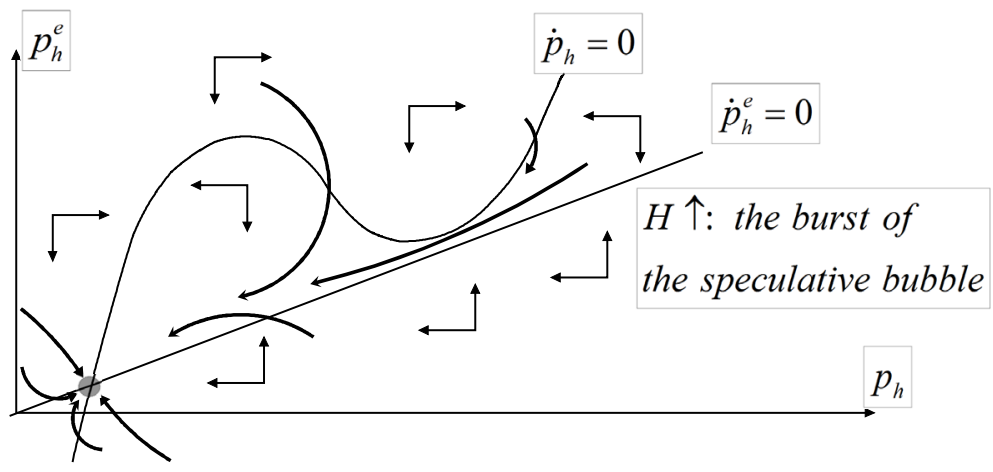

The points $p_{h 1}$ and $p_{h 2}$ are stable equilibria in the short run, as long as $H$, the housing stock, does not evolve. But $H$ is no more a given magnitude and starts to move. Boom situations are associated with upward adjusting housing supply, whereas busts interact with downward corrections of the supply. Nothing happens until the housing stock arrives at a sensible value that allows no more to maintain the prevailing equilibrium, but gives rise to a bifurcation point. The bifurcation set of the catastrophe manifold are exactly the short-run equilibrium positions $p_{h 1}$ and $p_{h 2}$ where the qualitative characteristic of the economic situ- 
ation turns around. These short-run equilibria have continuously moved to these states as a result of the slow motion of $H$. Taking a look at the lower equilibrium $p_{h 1}$, shows that the point of rest has moved that far downwards that no further movement in the same direction is possible along the housing demand curve. The downward shifting supply of houses therefore enforces the loss of the stable point here and necessitates a jump in $p_{h}$ to the right. A new stable equilibrium is established on the housing demand curve's descending right arm. The market jumps from a bust into a boom. Being initially in a boom, the description applies just the other way around.

The extension to the situation of backward-looking behavior is straightforward. The difference is that the singularities lie on the house market equilibrium curve in the $p_{h}, p_{h}^{e}$ space. Then the housing supply would only in the background determine the long-run position. As the analysis is of purely local nature, it only tells us that at the bifurcation points singularities exist which are of a fold catastrophe type and lead to qualitative changes of the economic characteristics.

Figure 6: Singularities, fold catastrophes and relaxation oscillations in the myopic perfect foresight case

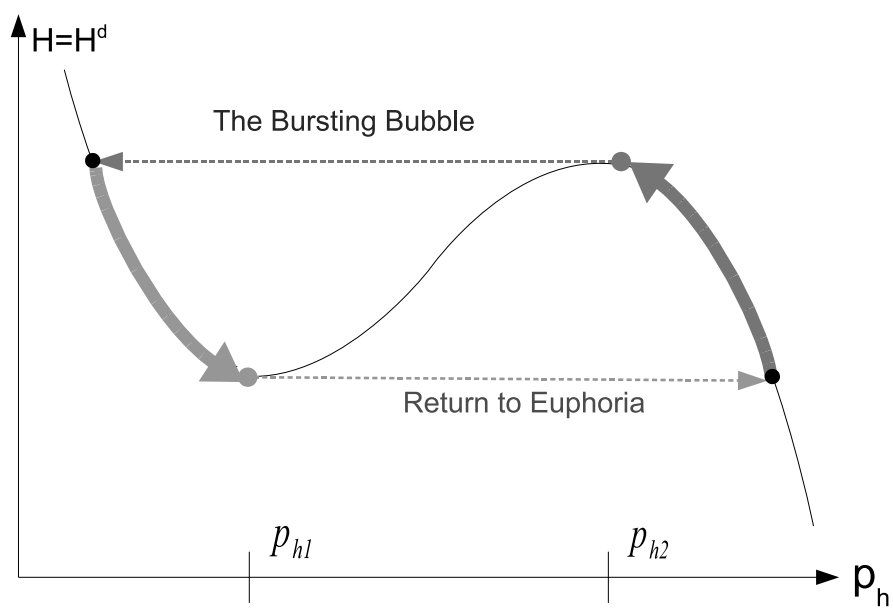

With only one law of motion left for the short-run, we are able to study the global dynamics of the housing market system in an easy way. Global dynamics are restricted to a compact domain in the $p_{h}, p_{h}^{e}$-space. All dynamics from outside this domain are attracted by it. All dynamics within the domain are bound in it. This is guaranteed by the motion of the housing stock which is in the short run a given parameter. As the stock becomes a slowly changing variable it continuously moves upward in association with boom states and shrinks in bust environments. This more long- run oriented view on the housing market shows the switching processes inherent. 
Figure 7: The long-run volatility of housing prices from the perspective of relaxation oscillations

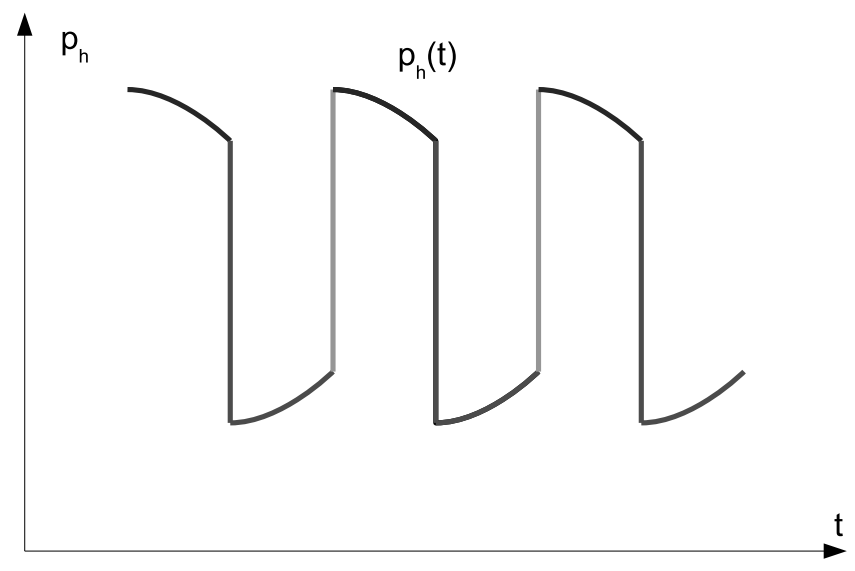

The movement of $H$ causes the prevailing (short-run)equilibrium to vanish eventually. Booms suddenly turn into busts, busts immediately turn into booms. But from a longrun perspective the process is stable in the sense that it repeats itself as long as the demand schedule remains fixed. Mathematically speaking the interaction of the short-run equilibria with the very sluggish adjustment in the supply of houses and subsequently the housing stock, gives rise to a stable relaxation oscillations limit cycle. Relaxations oscillations here come about because of the reduction in dimension of the model due to the transition of a dynamic into an algebraic equation. Being noted that it is necessary to demonstrate that the characteristics of the dynamics are not affected by this procedure. The method is only appropriate if the dynamics are structurally stable, meaning equivalent for finite adjustment speeds and the limit case.

Plotting these dynamic patterns for the housing price against time delivers ongoing wave-like fluctuations. Overtime an extremum is obtained, the price falls sharply down or increases rapidly. Figure 7 captures the course of the time pattern of $p_{h}{ }^{\text {. }}$

\section{Conclusions}

We have shown in this paper that a demand function for residential property which is upward sloping in housing prices in a midrange area of the price space (and as usual downward sloping outside of this range) can give rise to multiple equilibria under static housing price expectations. In addition, making such expectations endogenous through a simple adap-

I The relaxation of the assumption of myopic perfect foresight in favor of adaptive expectations would enable a better empirical fit of the time series. The vertical parts would flatten and could respectively show negative or positive slopes instead of jumps. 
tive adjustment, we show the existence of two stable and one (midrange) unstable equilibrium in the phase space composed of housing prices and their expected values. This situation also extends to the case of myopic perfect foresight as the natural limit case of adaptive expectations that adjust with ever increasing speed.

Next the basins of attraction of the obtained boom and bust situations were investigated in more detail and also their change in the case of a sluggishly adjusting supply of residential space, which lead to fold catastrophes for sufficiently large changes in the supply of houses. Combining these isolated boom and bust situations in a joint phase diagram, we finally showed from the global point of view the emergence of so called relaxation oscillations in the housing market where booms suddenly change into bust situations and vice versa when critical thresholds in the supply of residential space are passed, giving rise to the existence of boom-bust cycles in planar systems for myopic perfect foresight and in a $3 \mathrm{D}$ phase space in the case of adaptively formed house price expectations.

Future work along these lines should integrate a debt financing process (mortgages) into such boom-bust cycle generating mechanisms and consider the specific contributions of debt accumulation and of changes in the loan rate in the formation of such boom-bust cycles.

\section{References}

Baker, D. (2008): The housing bubble and the financial crisis, in: Real-world Economics Review, $46,73-8 \mathrm{I}$.

Chang, W.W., Smith, D.J. (197I): The existence and persistence of cycles in a nonlinear model: Kaldor's 1940 model re-examined, in: Review of Economic Studies, 38, 37 - 44.

Ferguson, N. (2008): The Ascent of Money. A Financial History of the World, New York: Penguin Press.

Flaschel, P. (2009): Macrodynamics: Elements for a Synthesis of Marx, Keynes and Schumpeter. Heidelberg: Springer, $2^{\text {nd }}$ edition.

Goodhart, C., Hofmann, B. (2008): House prices, money, credit, and the macroeconomy, in: Oxford Review of Economic Policy, 24 (I), $180-205$.

Kaldor, N. (1940): A model of the trade cycle, in: Economic Journal, 50, 78 - 92.

Lavoie, M. (1994): A Post Keynesian approach to consumer choice, in: Journal of Post Keynesian Economics, 16(4), 539-562.

Lavoie, M. (2004): Post Keynesian consumer theory: Potential synergies with consumer research and economic psychology, in: Journal of Economic Psychology, 25, 639-649.

Lorenz, H.-W. (1993): Nonlinear Dynamical Economics and Chaotic Motion, Heidelberg: Springer, $2^{\text {nd }}$ edition.

Minsky H. (1982): Can »It« Happen Again?, New York: M.E. Sharpe.

Muellbauer, J., Murphy, A. (2008): Housing markets and the economy: The assessment, in: $O x-$ ford Review of Economic Policy, 24 (I), I - 33.

Shiller, R.J. (2007): Understanding recent trends in house prices and home ownership, Economics Department Working Paper, No. 28. 
Schnure, C. (2005): Boom-bust cycles in housing: The changing role of financial structure, IMF Working Paper, No. 200.

Tu, P.N.V. (1994): Dynamical Systems, Heidelberg: Springer, $2^{\text {nd }}$ edition.

Varian, H. (1979): Catastrophe theory and the business cycle, in: Economic Inquiry, I7, I4-28. 
